\title{
Pembelajaran Matematika dan Bahasa Inggris dengan Metode Total Physical Response (TPR) di TK Al Firdaus Kandri Gunungpati Semarang
}

\author{
Yani Parti Astuti*1, Egia Rosi Subhiyakto ${ }^{2}$, Liya Umaroh ${ }^{3}$ \\ ${ }^{1,2}$ Universitas Dian Nuswantoro; jl. Imam Bonjol 207 Semarang, (+6224) 3517261 \\ ${ }^{3}$ Jurusan Teknik Informatika, Fasilkom Udinus, Semarang \\ e-mail: *1yanipartiastuti@dsn.dinus.ac.id, ${ }^{2}$ egia.rosi.subhiyakto@dsn.dinus.ac.id, \\ liya.umaroh@dsn.dinus.ac.id
}

\begin{abstract}
Abstrak
Dalam perkembangan ilmu pengetahuan di Indonesia, matematika dan bahasa inggris merupakan ilmu dasar yang harus dipelajari oleh setiap anak pelajar di Indonesia. Sehingga materi matematika dan bahasa inggris sudah dikenalkan sejak pendidikan anak usia dini. Namun di pendidikan anak usia dini hanya diajarkan berhitung untuk matematika dan pengenalan benda pada bidang bahasa inggris. Hal ini terjadi pada TK Al Firdaus Kandri Gunungpati Semarang. Di TK Al Firdaus ini anakanak sudah diajarkan mengeja huruf, berhitung dan juga bahasa inggris..Dalam pengabdian ini dikenalkan metode pembelajaran yang dinamakan Total Phycical Response (TPR). Metode ini merupakan metode pembelajaran di mana anak diajarkan materi dengan menggunakan gerakan. Hal ini paling cocok untuk materi bahasa inggris yang untuk mengenalkan benda dan juga melakukan suatu pekerjaan. Dalam materi matematika akan diselipkan juga materi berhitung dalam bahasa inggris dengan jari. Melalui pembelajaran ini, maka anak - anak di TK Al Firdaus semakin mencintai pelajaran berhitung dan bahasa inggris pada khususnya. Karena mengingat tempat TK Al Firdaus berada di desa wisata kandri. Sangat mendukung apabila generasi - generasinya pandai berbahasa inggris dan juga berhitung. Selain itu materi ini bisa untuk bekal memasuki jenjang berikutnya yaitu Sekolah Dasar (SD).
\end{abstract}

Kata kunci-Bahasa Inggris, berhitung, TPR

\begin{abstract}
In the development of science in Indonesia, mathematics and English are basic sciences that must be learned by every student in Indonesia. So that mathematics and English materials have been introduced since early childhood education. But in early childhood education is only taught to count for mathematics and object recognition in the field of English. This happened to Al Firdaus Kandri Gunungpati Semarang Kindergarten. In Al Firdaus Kindergarten, children have been taught to spell letters, counting and also English. In this dedication, a learning method called Total Phycical Response (TPR) is introduced. This method is a learning method where children are taught material by using movements. This is most suitable for English material that introduces objects and also does work. In math material will also be included counting material in English with fingers. Through this learning, the children in Al Firdaus Kindergarten increasingly love math and English in particular. Because remembering Al Firdaus Kindergarten is in the Candri tourist village. Very supportive if the generations are good at English and also counting. In addition this material can be used to enter the next level, namely Elementary School $(S D)$.
\end{abstract}

Keywords-English,

\section{PENDAHULUAN}

Menurut UU No. 20 Tahun 2003 tentang Sistem Pendidikan Nasional Bab 1, pasal 1, butir 14 dinyatakan bahwa "Pendidikan Anak Usia Dini adalah suatu upaya pembinaan yang ditujukan kepada anak sejak lahir sampai dengan usia enam tahun yang dilakukan melalui 
pemberian rangsangan pendidikan untuk membantu pertumbuhan dan perkembangan jasmani dan rohani agar anak memiliki kesiapan dalam memasuki pendidikan lebih lanjut".

Pendidikan Anak Usia Dini di Indonesia biasa disebut dengan PAUD lalu dilanjutkan dengan Taman Kanak - kanak. Pada pembelajaran PAUD hanya dikenalkan tentang sosialisasi, bermain dan juga gerak dan lagu. Hal ini karena pada PAUD rata - rata usianya di bawah 4 tahun. Sedang anak - anak yang berusia dari $4-6$ tahun sudah menduduki jenjang Taman Kanak - Kanak (TK). Pembelajaran di usia TK biasanya sudah diajarkan tentang berhitung, membaca dan juga bahasa inggris selain bermain. Sehingga pembelajaran di TK dibutuhkan keahlian khusus dalam mengajarkan mereka agar bisa menyenangkan. Rata - rata pembelajaran di TK anak - anak sudah dipenuhi dengan hafalan.

Karena setiap anak mempunyai kemampuan yang berbeda - beda, maka kadang anak merasa bosan atau malas dalam hafalan. Tapi ada juga anak yang sudah mampu menghafal segala macam pelajaran yang diberikan di TK. Untuk itu semua guru TK harus mempunyai metode khusus untuk menjembatani masalah tersebut.

Sebagai contoh pada TK Al Firdaus yang mempunyai dua kelas yaitu TK A dan TK B. TK A adalah pendidikan anak usia dini yang berumur 4-5 tahun. Sedang TK B berumur 5-6 tahun. Di TK ini sudah diajarkan bahasa inggris karena mengingat bahasa inggris adalah bahasa yang penting di manapun. Dari perkembangan elektronik akan banyak juga petunjuk menggunakan bahasa inggris. Untuk itu harus dibutuhkan cara yang baik dan juga menyenangkan dalam mengajarkan bahasa inggris kepada anak - anak usia dini.

Berdasarkan uraian di atas, maka perlu adanya metode yang harus digunakan pada anak usia dini dalam belajar bahasa inggris agar mereka tidak bosan dan cepat menghafalnya. Metode yang akan digunakan adalah metode Total Physical Response (TPR). Metode ini mengajarkan untuk menghafal kosa kata bahasa inggris dengan menggunakan gerakan. Selain kosa kata, diajarkan juga berhitung cepat dengan bahasa inggris.

\section{METODE PENELITIAN}

Pelaksanaan pengabdian diawali dengan survey ke tempat pengabdi yaitu di TK Al Firdaus Kandri Gunungpati Semarang. Di sana bertemu dengan ibu kepala sekolah dan beliau menceritakan kurikulum yang ada di TK tersebut. Dengan kurikulum yang ada di TK itu, maka team pengabdi melakukan persetujuan mitra. Pada hari pelaksanaan kegiatan pengabdian metode yang digunakan mengarah pada permainan yang tidak formal. Diawali dengan materi berhitung menggunakan bahasa inggris, lalu menunjuk benda - benda sekitar dengan bahasa inggris dan diakhiri dengan menunjuk anggota tubuh dengan bahasa inggris yang disertai dengan menyanyi.

\section{HASIL DAN PEMBAHASAN}

Ada beberapa hasil yang dicapai pada pengabdian ini, diantaranya adalah sebagai berikut:

1. Siswa mampu berhitung dengan menggunakan jarinya dengan benar dan bisa menyebutkannya dalam bahasa inggris 


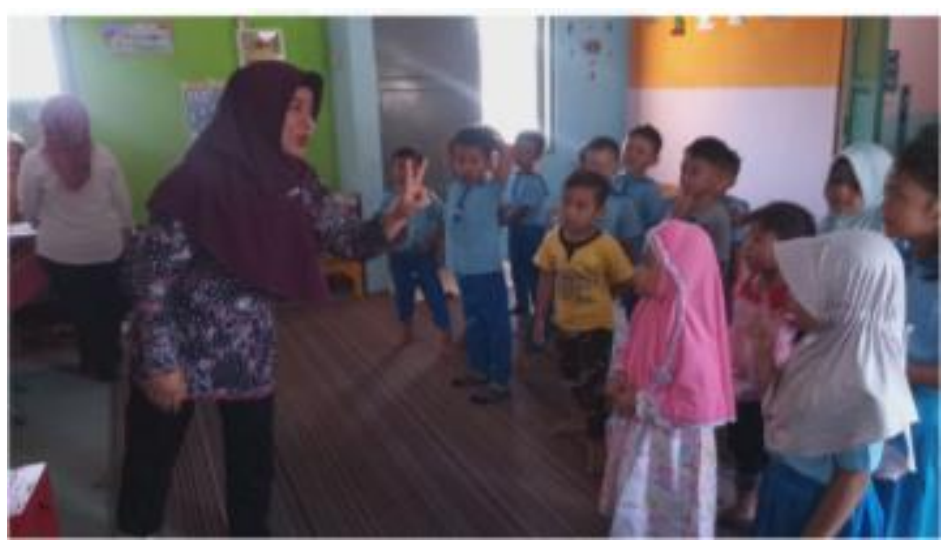

2. Siswa mampu menyebutkan beberapa benda dengan menggunakan bahasa inggris

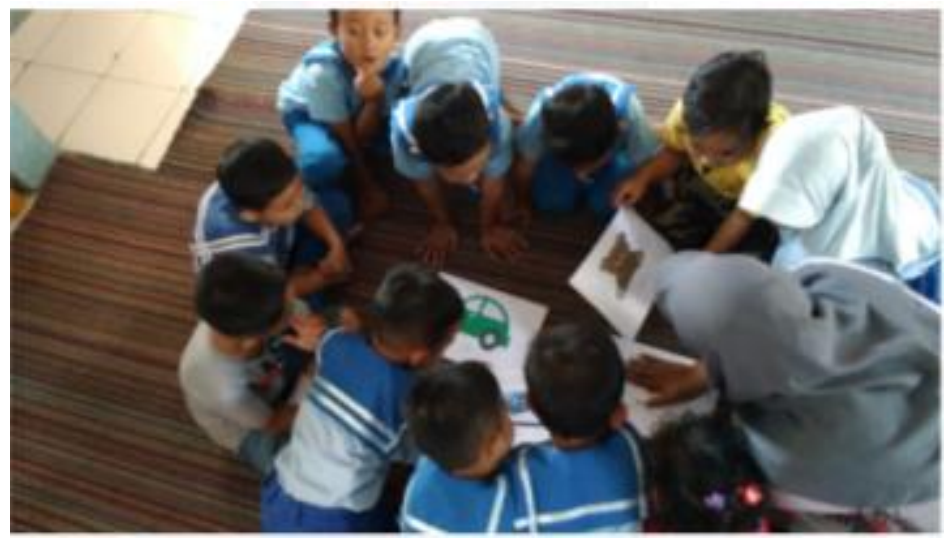

3. Siswa mampu mengkombinasikan gerakan menunjuk anggota tubuh dengan bahasa inggris yang dilakukan berulang - ulang

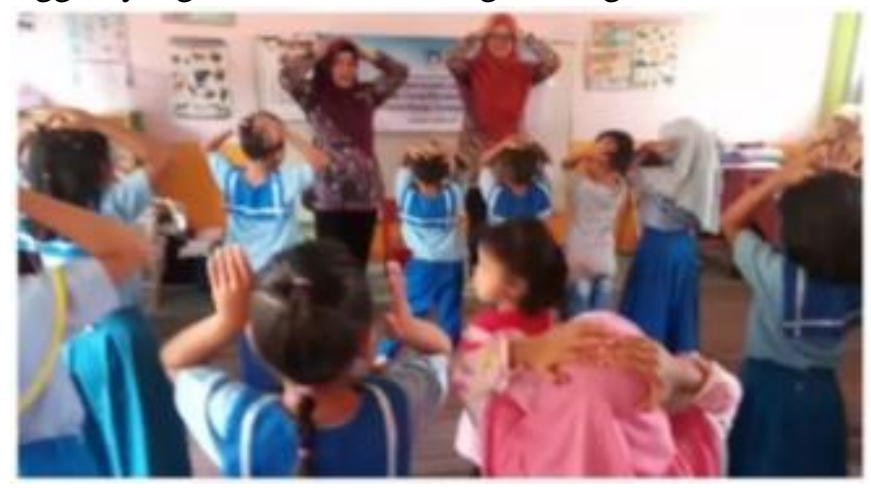

Pada pengabdian ini didapat luaran sebagai berikut :

1. Mengunggah kegiatan pengabdian ke dalam youtube dengan alamat

2. Menghasilkan artikel yang diunggah di abdimasku.lppm.dinus.ac.id 


\section{KESIMPULAN}

Pada pengabdian ini dapat diambil suatu kesimpulan sebagai berikut

1. Metode TPR sangat cocok diterapkan dengan anak - anak usia dini karena sambil menunjuk suatu benda atau anggota tubuh, siswa bisa cepat menghafal.

2. Metode TPR dapat membantu seorang pendidik usia dini untuk membantu anak didiknya berlatih bahasa inggris dengan bermain sambil menunjuk pada apa yang diinginkan

\section{SARAN}

Setiap kegiatan pasti ada kekurangannya. Begitupun dalam kegiatan pengabdian ini. Dalam kegiatan ini masih belum optimal dalam mengenalkan berbagai macam benda. Pada kesempatan lain bisa dikembangkan oleh guru di TK Al Firdaus agar siswa - siswanya dapat menghafal bahasa inggris dengan mudah.

\section{UCAPAN TERIMA KASIH}

Pengabdian masyarakat ini terlaksana berkat bantuan dana dari LPPM Udinus Semarang. Untuk itu dalam tulisan ini kami mengucapkan terima kasih kepada LPPM Udinus Semarang, Team Pengabdi, Semua pihak TK Al Firdaus Kandri Gunungpati Semarang, Ibu Nisaul Hafidhoh yang ikut meramaikan kegiatan ini.

\section{DAFTAR PUSTAKA}

Undang - Undang No. 20, Sistem Pendidikan Nasional, 2003

Peraturan menteri pendidikan dan kebudayaan republik indonesia nomor 84 tahun 2014 tentang pendirian satuan pendidikan anak usia dini

F Fauzia, Metode TPR (total physical response) sebagai alternatif untuk meningkatkan kemampuan tahap awal berbahasa Inggris pada anak, JPIP Vol 9, Nomor 1, Maret 2016

Newmark, P. ( 1991). About translation. Clevedon [England]: Multilingual Matters. England.

Dwiastuty, Pembelajaran bahasa inggris melalui metode total physical response, Faktor Jurnal Ilmiah Kependidikan, vol 3 no 1, 2016 